\title{
Nasal dermoid cysts with intracranial extension: avoiding coronal incision through midline exposure and nasal bone osteotomy
}

\author{
Chad A. Purnell, MD, ${ }^{1}$ Rachel Skladman, BA, ${ }^{2}$ Tord D. Alden, MD, ${ }^{3}$ Julia F. Corcoran, MD, ${ }^{1}$ and \\ Jeffrey C. Rastatter, MD4
}

${ }^{1}$ Department of Plastic Surgery, Shriner's Hospitals for Children; ${ }^{2}$ Rush Medical College; and Departments of ${ }^{3}$ Neurosurgery and ${ }^{4}$ Otolaryngology/Head and Neck Surgery, Ann \& Robert H. Lurie Children's Hospital of Chicago, Illinois

\begin{abstract}
OBJECTIVE Up to $10 \%$ of midline nasal dermoid cysts have intracranial extension. Previous techniques of excision include frontal and frontonasal craniotomies via a coronal approach, combined with a direct cutaneous excision of the dermoid cyst. While the coronal incision allows for wide visualization, it carries significant risks of transfusion, blood loss, and scarring. The authors present an alternative technique in which access is gained through a midline extension of the dermoid cyst excision that provides direct access for a keyhole frontal craniotomy.

METHODS The authors utilize a nasal bone osteotomy, pericranial flap, and keyhole-type craniotomy performed through a nasal midline incision for the treatment of nasal dermoid cysts with intracranial extension. They performed a retrospective chart review of all patients with nasal dermoid cysts treated at the Ann \& Robert H. Lurie Children's Hospital of Chicago from 2009 to 2017. Patient demographic data, operative data, and in- and outpatient complication data were collected.
\end{abstract}

RESULTS In 10 patients with cyst extension near or into the intracranial cavity (7 with true intracranial extension), the nasal osteotomy technique was performed. The mean blood loss was $13 \mathrm{ml}$, with a $0 \%$ transfusion rate. The mean length of inpatient stay was 1 day. A durotomy was made and repaired as part of the dermoid cyst dissection in 3 patients. One patient underwent intraoperative placement of a lumbar drain. The mean operative time was 228 minutes. There were no intraoperative or postoperative complications, including the need for a reoperation. No patients had any long-term complications, and no patients have had dermoid cyst recurrence. The appearance of the scar was acceptable in all cases.

CONCLUSIONS The midline approach to nasal dermoid cysts with intracranial extension is safe and results in limited blood loss, short operative times, and short lengths of inpatient hospital stay. This is a viable technique for the treatment of this challenging pathology.

https://thejns.org/doi/abs/10.3171/2019.9.PEDS19132

KEYWORDS intracranial dermoid; keyhole craniotomy; frontal craniotomy; nasal bone osteotomy; surgical technique

$\mathrm{N}$ ASAL dermoid cysts are rare congenital lesions that account for $61 \%$ of midline nasal masses in children. ${ }^{2}$ Occurring due to failure of regression of the neuroectodermal tract during weeks 4-8 of gestation, these cysts contain both mesoderm and ectodermal elements but no endoderm. ${ }^{23}$ In evaluation of a midline nasal lesion in children, consideration of a nasal dermoid lesion is mandatory as intracranial extension may occur. Most recently, in the largest series of nasal dermoid cysts, $10 \%$ had a tract that included intracranial extension. ${ }^{3}$ These lesions can predispose patients to significant sequelae, such as local infection or even intracranial infection, including meningitis and brain abscess. Furthermore, appropriate surgical planning is essential, as incomplete removal of a dermoid cyst or sinus results in 50\%-100\% recurrence rates. ${ }^{1}$ Once intracranial extension is identified, a myriad of treatment methods have been described. For the majority of cases in the literature, frontal or frontonasal craniotomy is performed, typically combined with an external nasal approach to the cyst. ${ }^{1,14,15,17,20,21}$ Some authors also describe minimal access craniotomies or endoscopic treatment if the dermoid tract anatomy is favorable., ${ }^{4,16}$ While a coronal approach provides excellent visualization of the dermoid tract, it also involves a large incision with risks for unfavorable scarring. Conversely, endoscopic techniques minimize incision burden but at the price of challenging 


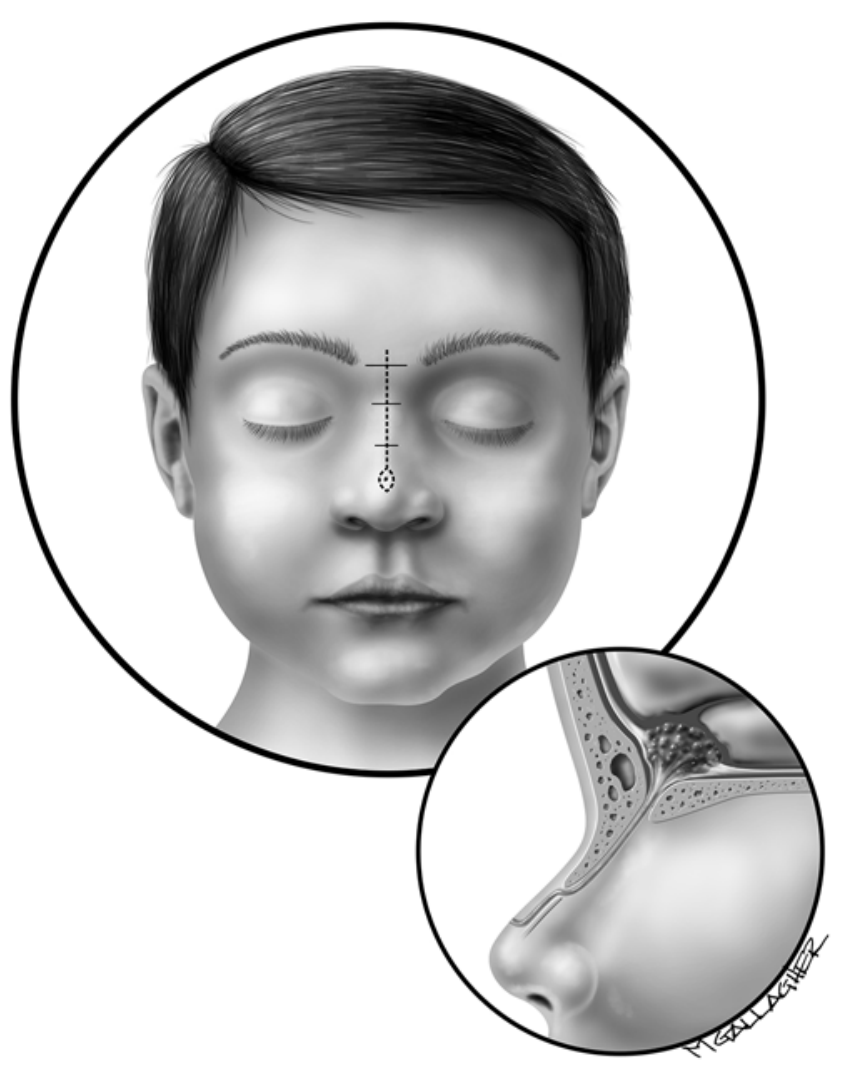

FIG. 1. Incision design for nasal midline incision. The supratip, nasal radix, and glabella are marked as important landmarks for reapproximation. The incision should not extend past the radix, if possible, for maximum cosmesis. Artist: Mike Gallagher. Copyright Jeffrey C. Rastatter. Published with permission.

visualization and a limited ability to precisely dissect the dermoid tract from surrounding tissues. Over the past 9 years, we at the Ann \& Robert H. Lurie Children's Hospital of Chicago have endeavored to develop a technique for access to dermoid cysts with intracranial extension that balances the wide exposure of a coronal approach with the shorter scar of more minimally invasive techniques. In this article, we present our series of patients in whom we used a midline incision with subcranial approach and keyhole-type craniotomy to treat nasal dermoid cysts with intracranial extension.

\section{Methods}

\section{Surgical Technique}

An ellipse is marked around any cutaneous sinus tract or punctum. A vertical midline incision is extended superiorly from this. Horizontal marks are placed at the inferior extent of the nasal bones (to mark the area where bone removal will begin) and the radix. We have noted that if the incision is extended above the radix it is much more noticeable, so we attempt not to incise above this line if at all possible (Fig. 1). The skin ellipse is incised first and the tract identified. A combination of sharp and blunt dissection is used to dissect the tract in continuity until it extends to the nasal bones. While the tract may extend superior

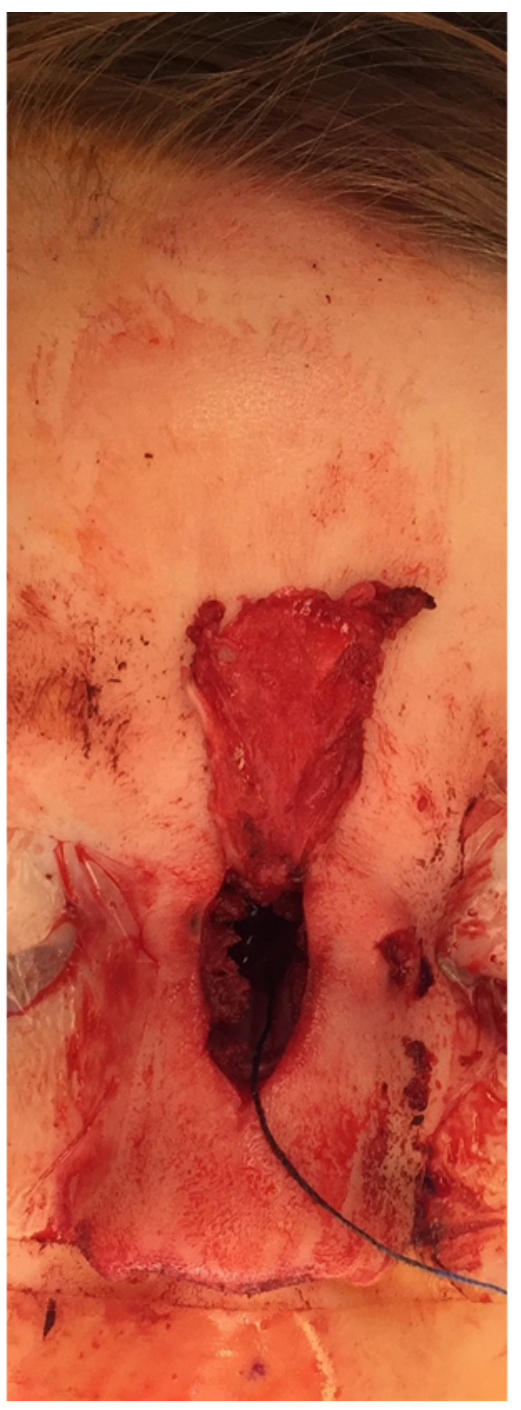

FIG. 2. Pericranial flap harvested through a midline incision for later coverage of dural repair. Figure is available in color online only.

to, through, or inferior to the nasal bones, we have often observed this in a plane between the upper lateral cartilages and the bone. Our technique is most applicable if the tract runs deep to or through the nasal bones. Prior to nasal bone osteotomy, through this midline incision, a pericranial flap is designed on one of the supratrochlear arteries and dissected subperiosteally (Fig. 2). The flap is banked in the forehead for later use. An osteotomy of the nasal bones is designed and performed with a $3-\mathrm{mm}$ osteotome (Fig. $3)$. The tract can often be dissected and removed en bloc with the nasal bones (Fig. 4). The tract is then transected as it enters the substance of the frontal bone. At this point, a burr is used to remove bone around the tract in order to gain access to the intracranial component of the dermoid lesion (Fig. 5). After removal of the intracranial portions, the dura mater is repaired primarily or patched with collagen matrix, as needed (Fig. 6). The pericranial flap is tunneled to cover the dura and fixated with fibrin glue (Fig. 7). Nasal bones can be replaced with overlying bridging 3-0 polyglactin sutures or, in many cases, can be directly su- 


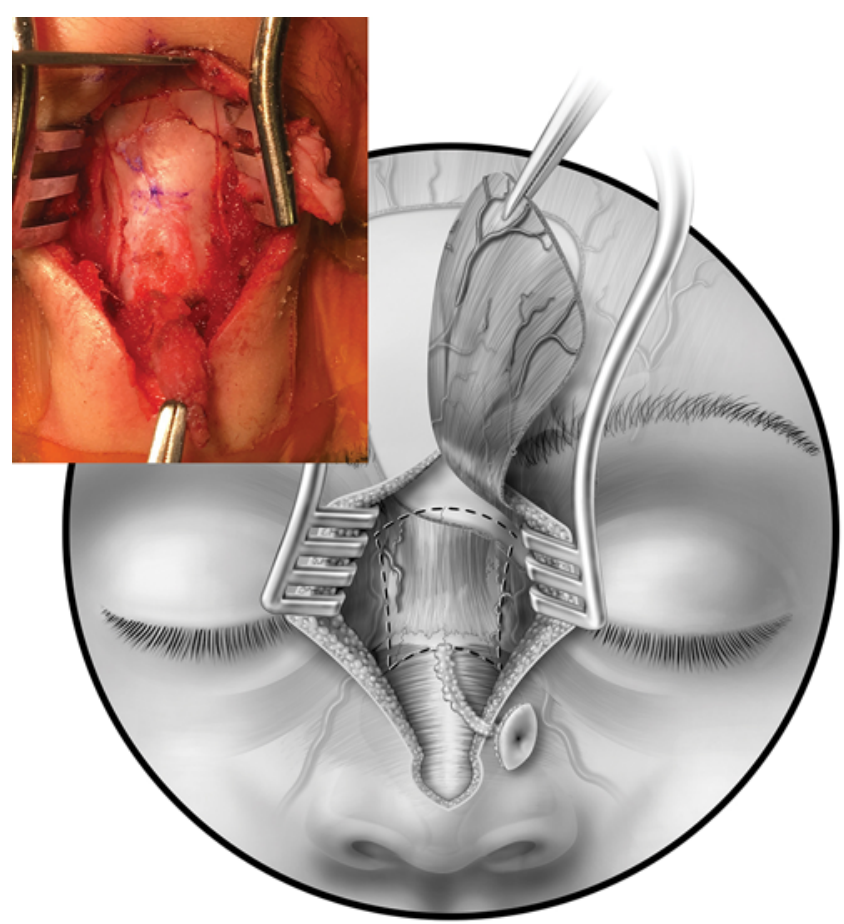

FIG. 3. Nasal bone osteotomy designed superior to where the sinus tracks deep to the bone. Inset: Nasal bones in situ showing the osteotomy. Artist: Mike Gallagher. Copyright Jeffrey C. Rastatter. Published with permission. Figure is available in color online only.

tured back into place, given the thin bone seen in this age group (Fig. 8). The skin is closed with 4-0 polyglactin deep dermal sutures and 6-0 PROLENE simple interrupted sutures, which are removed on postoperative day 5 .

\section{Chart Review}

After receiving institutional review board approval, we performed a retrospective chart review of all patients with nasal dermoid cysts operated on by the plastic surgery, otolaryngology, or neurosurgery services at our institution from 2009 to 2017. Patients were identified through Current Procedural Terminology (CPT) codes 30124 and 30125. Demographic data, operative data, and inpatient care and outpatient follow-up data were collected. Patients were divided into those who had a nasal bone removed as part of the lesion excision and those who did not.

\section{Results}

From 2009 to 2017, 10 patients required a nasal bone removal procedure; these 10 cases represented $29 \%$ of all suspected midline dermoid cysts excised at our institution. Details of these patients are provided in Table 1. Of these, 7 patients had true intracranial extension of the cyst that required a frontal craniotomy via the subcranial approach. No frontal craniotomies for dermoid cysts were performed through a coronal incision during the study period.

Of the 10 patients in whom nasal bone was removed, 3 had significant comorbidities, including a tracheoesophageal fistula and severe gastroesophageal reflux; Goldenhar syndrome with cardiac defects; and a prior myelomeningo-

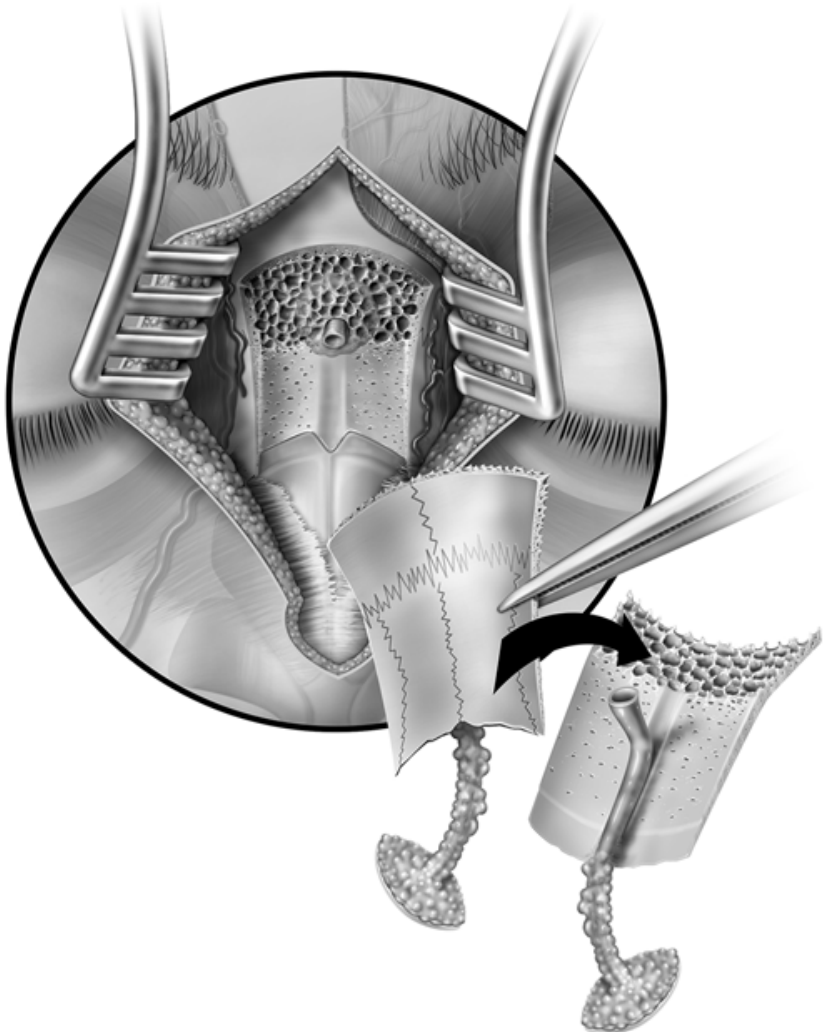

FIG. 4. Nasal bones removed with the sinus tract on the deep surface of the nasal bones. The arrow indicates the action of turning over the removed nasal bones, thereby providing a view of the undersurface, or the deep surface of the nasal bones and associated sinus tract. Artist: Mike Gallagher. Copyright Jeffrey C. Rastatter. Published with permission.

cele. Operations were performed when the patients were a mean of 2.3 years of age (range 8 months to 8.2 years). The mean operative duration was 228 minutes (range 129-307 minutes); the mean estimated blood loss was $13 \mathrm{ml}$ (range 2-50 ml); and the mean length of stay was 1 day, with one patient without intracranial extension of the cyst undergoing outpatient surgery and one patient with a maximum hospital stay of 5 days. The mean follow-up duration was 458 days (range $27-1145$ days). A durotomy was made and repaired as part of tract dissection in 3 patients. In one of these patients, a lumbar drain was placed intraoperatively to treat continuous CSF leakage through the dural repair. There were no other intraoperative or postoperative complications, including the need for a reoperation. No patients received a blood transfusion. No patients had any long-term sequelae related to the procedure, and no patients have had a dermoid cyst recurrence (Fig. 9).

\section{Discussion}

Nasal dermoid cysts, with deep extension, approaching or entering the anterior cranial fossa present a challenging, multidisciplinary problem. Aggressive and complete excision of the dermoid tract is mandatory, as there is a 50\%$100 \%$ recurrence rate in cases of excisions with incompletely resected margins. ${ }^{14}$ Furthermore, remnants of the 


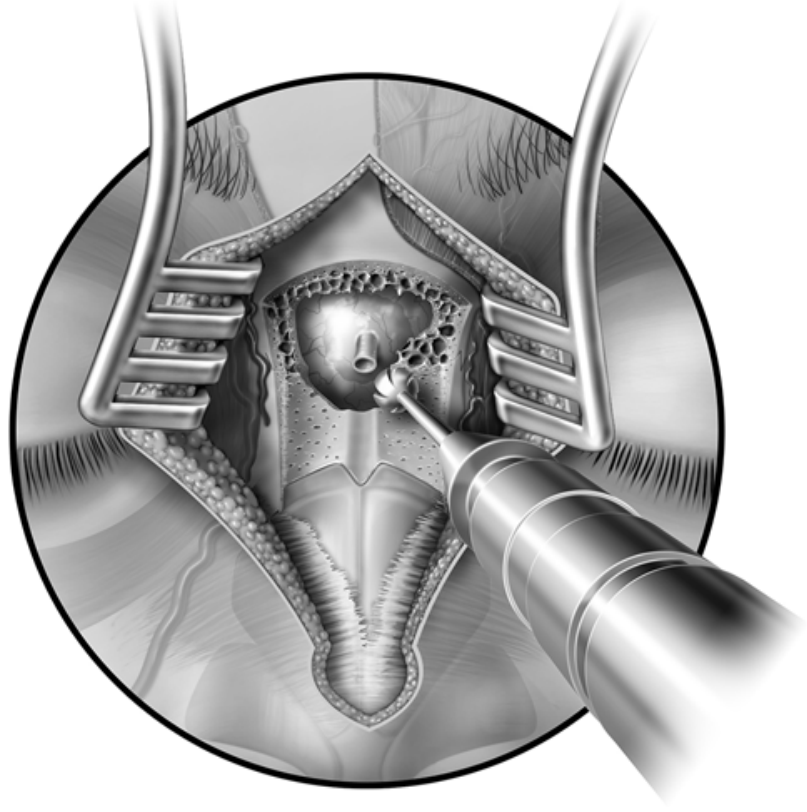

FIG. 5. The drill used to expose the intracranial portion of the dermoid cyst. Artist: Mike Gallagher. Copyright Jeffrey C. Rastatter. Published with permission.

epithelial lining may cause persistent, recurrent infections, which can range from cellulitis to meningitis. Thus, according to Pollock, the surgical technique for the excision of nasal dermoid cysts should follow 4 main principles: 1) it should allow complete access to cysts and associated sinus tract and allow for medial and lateral osteotomies; 2 ) it should allow access to the skull base; 3 ) it should provide exposure for the reconstruction of the nasal dorsum; and 4) it should result in a cosmetically acceptable scar..$^{13}$ Unfortunately, these principles are often at odds with one another, as improved exposure comes at the expense of a larger incision and a larger scar.

If a dermal sinus has an extension to the skin, a combined intracranial-extracranial approach is required for complete resection. The most common external incisions include the following: vertical midline, transverse linear or curvilinear, lateral rhinotomy, open rhinoplasty, and glabellar..$^{5,11}$ Techniques for intracranial excision have focused on a frontal craniotomy with or without a keystone osteotomy, smaller keystone osteotomies, and endoscopic treatment.

A frontal craniotomy with or without a keystone osteotomy of the supraorbital bandeau and nasal bones offers the most complete exposure to the intracranial portion of the cyst. . $14,15,17,20,21$ However, a frontal craniotomy is a morbidity-causing procedure that requires frequent blood transfusion, as high as $100 \%$ in many series. ${ }^{6,7,10}$ This exposure mandates significant brain retraction, longer operative time, and longer hospital stay. Studies comparing frontal craniotomy to the transglabellar/subcranial approach for the resection of anterior skull base neoplasms have found significantly greater morbidity associated with the frontal craniotomy approach. ${ }^{6,7}$ A large craniotomy also increases the risk of dural or sinus injury, which may

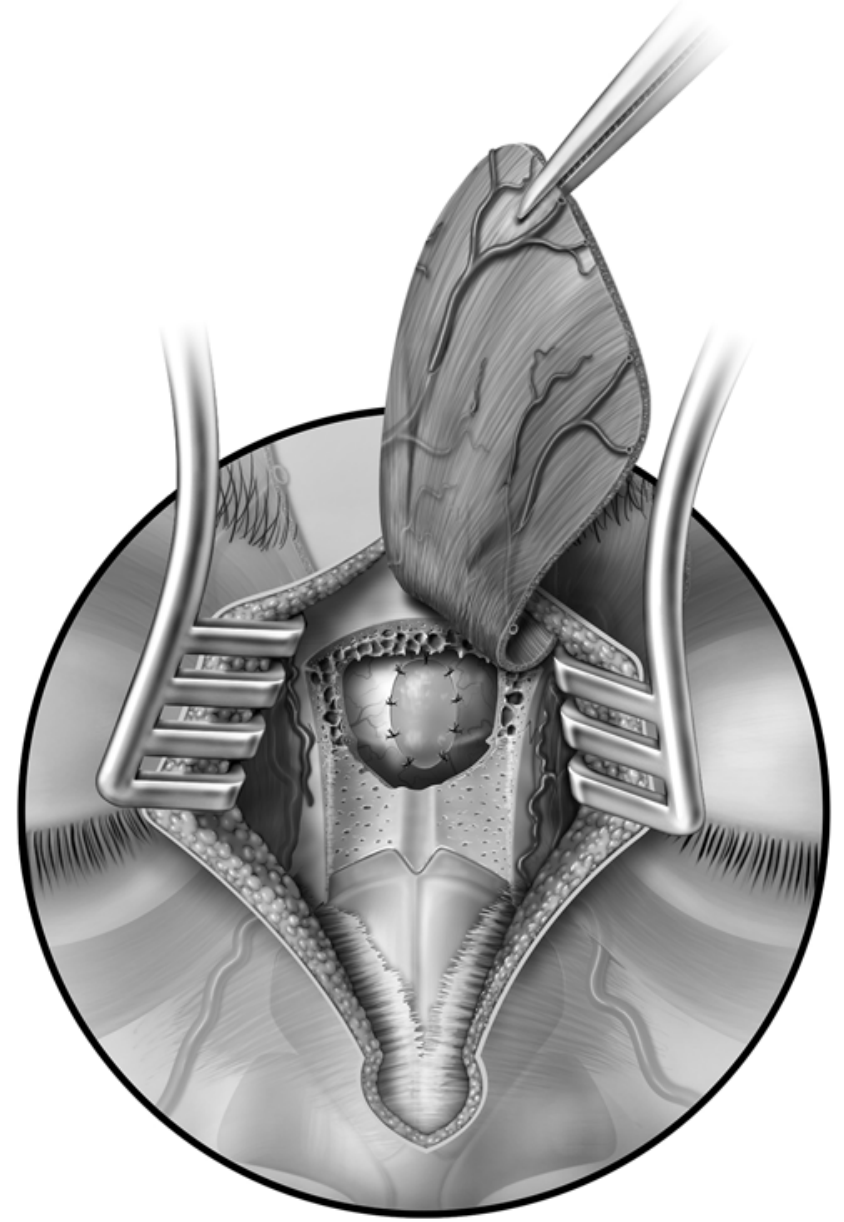

FIG. 6. Patch closure of the durotomy after removal of the intracranial portion. Artist: Mike Gallagher. Copyright Jeffrey C. Rastatter. Published with permission.

also result in significant morbidity. ${ }^{4}$ To obviate some of these disadvantages, more minimal access keyhole-type craniotomies have been suggested.

Endoscopic removal of nasal dermoid cysts that extend intracranially has gained popularity as a technique with a lower morbidity rate than that of a frontal craniotomy.,12, 16,18,19,22 Endoscopic excision allows for minimal external incisions but does not obviate the need for a midline nasal incision if there is a visible punctum. However, endoscopic techniques may not be applicable to all dermoid cysts with intracranial extension, especially those that have large cutaneous components or complex intracranial extension that require more involved dural repair. Furthermore, this approach has a steep learning curve from both an otolaryngology and neurosurgery standpoint and may not be available at all centers. ${ }^{22}$

We believe that the optimal technique for excision of nasal dermoid cysts is one that maximizes exposure of the cyst and the sinus tract while maximizing cosmesis. An ideal technique should also minimize blood loss and the risk of infection and allow for easy repair of dural defects, should they arise. Thus, we propose a technique that combines a midline incision with a subcranial approach and 


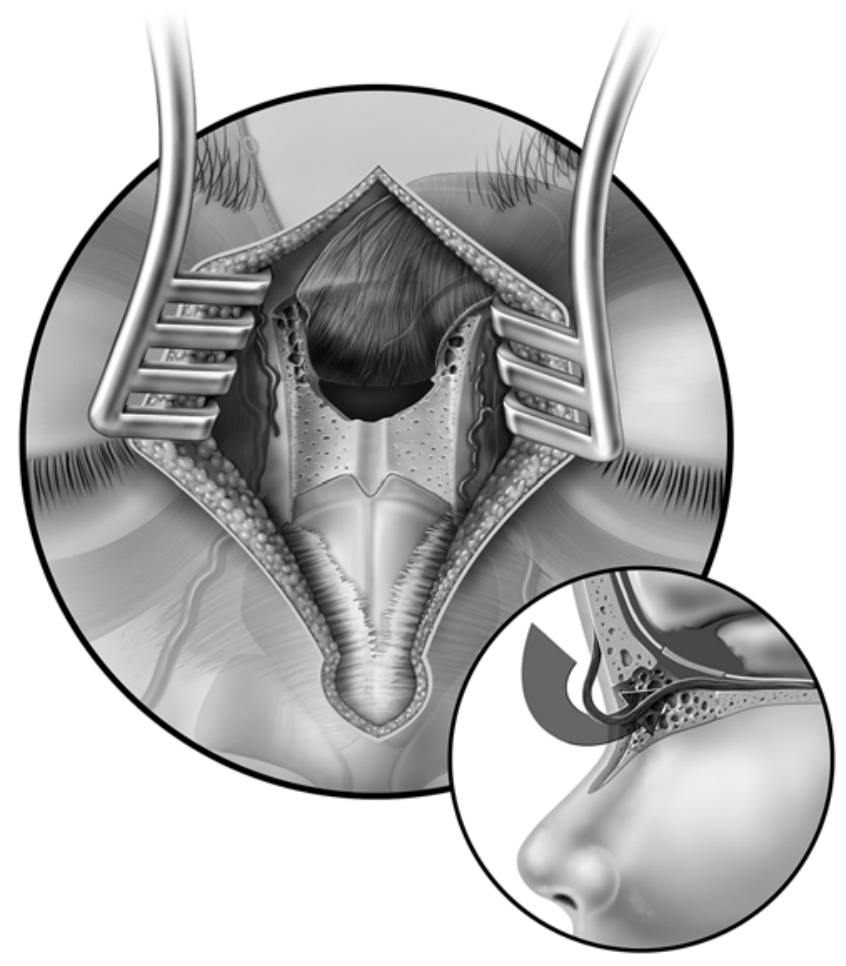

FIG. 7. Placement of the pericranial flap to bolster dural repair and decrease intracranial dead space. Inset: Sagittal view of the placement. The arrow indicates the action and trajectory of placing the pericranial flap in the proper plane between the bone and dura. Artist: Mike Gallagher. Copyright Jeffrey C. Rastatter. Published with permission.

keyhole frontal craniotomy. A midline incision was the first technique used for excision of the extracranial component of a nasal dermoid lesion. ${ }^{15}$ A vertical midline incision is required for excision of the cutaneous extension of the dermoid sinuses and can easily be extended incrementally for further access. ${ }^{11}$ Nasal bone removal allows clear visualization of the entire sinus tract, from the subcutaneous nasal surface to its communication with the anterior cranial fossa. Because we do not have to fragment the

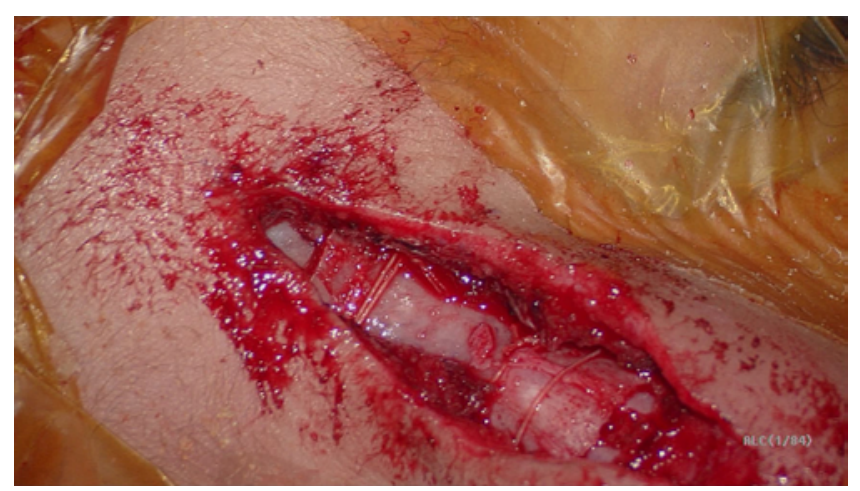

FIG. 8. Intraoperative photograph showing nasal bones secured with spanning sutures. Figure is available in color online only.

dermoid, the chance of leaving any dermoid tissue behind is very low. At this point, the frontal keyhole craniotomy can be designed to be as large as is required, without the need for extensive frontal lobe retraction. This technique affords wide exposure through a relatively small incision, improving the surgeon's ability to address the intracranial component of the cyst without endoscopy. Furthermore, a pericranial flap can also be elevated through this exposure, providing additional vascularized tissue for dural repair or separation of the nasal cavity from the craniotomy site.

Unfortunately, very few prior studies of the treatment of midline intracranial dermoid cysts provide intraoperative data, such as the need for transfusion, blood loss, or operative time. Schuster et al. have described an endoscopic transnasal resection in 2 patients, who remained in the hospital for 2 and 5 days. ${ }^{18}$ Heywood et al. have reported on 27 patients who underwent a transglabellar, small-window craniotomy, and they noted that patients were discharged within 2 days. ${ }^{4}$ Comparative studies of transglabellar/subcranial craniotomies versus traditional frontal craniotomies for anterior cranial fossa tumor resections have noted that the transglabellar craniotomy had lower mean blood loss (range 504-536 ml for benign tumors) and hospital stays from 5 to 7 days. ${ }^{6-8}$ In these series, the traditional frontal craniotomy had even higher blood loss, transfusion rates, and hospital stays. While it is

TABLE 1. Summary of data for 10 patients undergoing nasal bone removal for excision of a midline nasal dermoid cyst

\begin{tabular}{rrrrrrrr}
\hline $\begin{array}{c}\text { Patient } \\
\text { No. }\end{array}$ & $\begin{array}{c}\text { Age } \\
(\mathrm{mos})\end{array}$ & $\begin{array}{c}\text { Intracranial } \\
\text { Extension }\end{array}$ & Comorbidities & $\begin{array}{c}\text { Op Time } \\
\text { (mins) }\end{array}$ & $\begin{array}{c}\text { Blood Loss } \\
\text { (ml) }\end{array}$ & $\begin{array}{c}\text { Length of Stay } \\
\text { (hrs) }\end{array}$ & $\begin{array}{c}\text { Follow-Up } \\
\text { (days) }\end{array}$ \\
\hline 1 & 8.1 & Yes & & 266 & Minimal & 16 & 97 \\
\hline 2 & 39.2 & Yes & & 222 & 50 & 11.9 & 27 \\
\hline 3 & 15.4 & Yes & TEF, multiple anomalies & 307 & NR & 48 & 328 \\
\hline 4 & 8.9 & Yes & & 295 & 10 & 120 & 825 \\
\hline 5 & 10.2 & Yes & & 247 & 14 & 64 & 496 \\
\hline 6 & 25.8 & Yes & & 214 & 5 & 16 & 503 \\
\hline 7 & 36.9 & Yes & & 215 & 2 & 24 & 503 \\
\hline 8 & 14.9 & No & & 176 & 13 & 24 & 1145 \\
\hline 9 & 99.4 & No & Goldenhar syndrome, cardiac defects & 129 & 5 & Outpatient & 131 \\
\hline 10 & 14.0 & No & Previous myelomeningocele, VP shunt & 220 & 5 & 16.75 & 524 \\
\hline
\end{tabular}

$\mathrm{NR}=$ not recorded; $\mathrm{TEF}=$ tracheoesophageal fistula; $\mathrm{VP}=$ ventriculoperitoneal. 

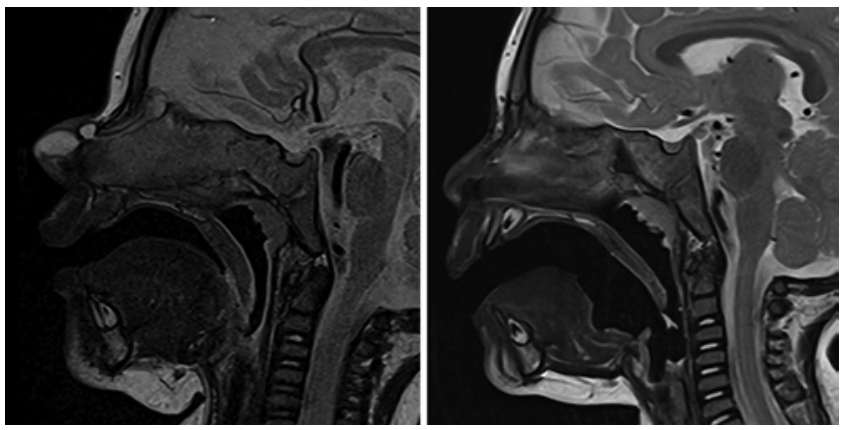

FIG. 9. Left: Preoperative sagittal T2-weighted MR image of a 2-yearold patient with a nasal dermoid cyst with intracranial extension.

Right: Postoperative 1-year sagittal MR image showing no residual dermoid cyst or tract.

important to note that intracranial dermoid cyst excisions are not directly comparable to anterior cranial fossa tumor resections, this cohort's data provide the best comparison to our data. Our technique of midline incision with nasal bone removal has a comparatively lower blood loss of 13 $\mathrm{ml}$, a $0 \%$ transfusion rate, and a mean 1-day length of stay, a significant improvement over previous cohorts, even including those in which endoscopic techniques were used. We believe it is the combination of direct access and wide exposure that allows our approach to have lower operative times that result in less blood loss.

A frontal craniotomy through a coronal incision can result in a nearly invisible scar hidden behind the hairline. However, this also results in compromises in exposure, blood loss, operative time, and need for brain retraction compared to a midline exposure. It is not our assertion that a midline exposure results in a more esthetic result than a coronal incision but instead that it is an additional option in these cases that can result in an esthetically acceptable scar if planned appropriately. In patients who already have a cutaneous sinus or dermoid lesion that needs to be excised, a midline incision is unavoidable, and extending this incision may not result in a significantly worse esthetic result. Both options can be considered, with the approach

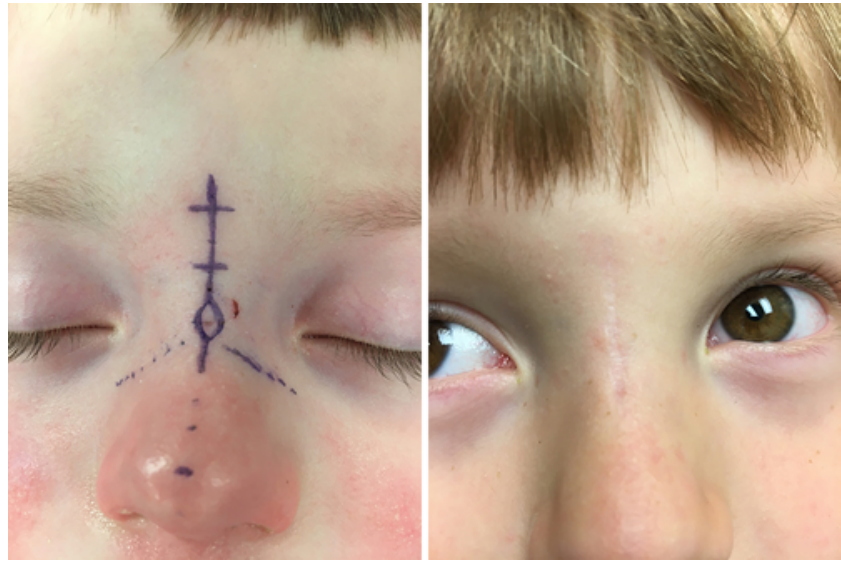

FIG. 11. Left: Intraoperative incision design for a patient prior to excision of a dermoid cyst with intracranial extension. Right: The appearance of the scar 9 months postoperatively, showing good cosmesis. Figure is available in color online only.

that is chosen based on lesion anatomy, comorbidities, and surgeon or family preference.

While a vertical midline incision provides excellent access, it has the disadvantage of being located in the central portion of the face. In order to maximize the esthetic outcomes from this approach, we recommend several technical modifications. The midline incision should only be extended as far as needed to excise the punctum and to provide access to the nasal bones for osteotomy. Z-plasties can be used carefully at junctions of the supratip and dorsum, as well as the junction of the dorsum and glabella, to minimize scar contraction. With meticulous care of incisions at home and careful layered closure, we have had good results with a thin-line scar (Figs. 10-12).

There are several potential disadvantages to this technique that must be weighed. As discussed above, a vertical midline incision requires careful planning and postoperative care to optimize scarring. While we have not noted any nasal growth disturbance associated with this technique, this is not being formally followed with cephalometrics, and our follow-up period is likely too short to cap-
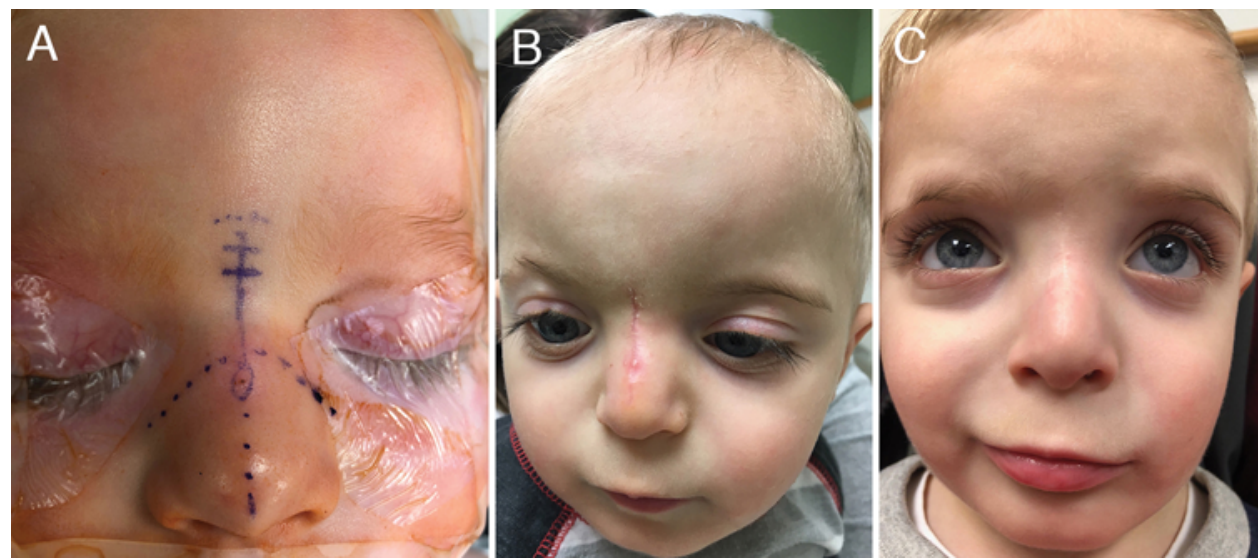

FIG. 10. A: Intraoperative incision design for a 16-month-old boy with a dermoid sinus cyst with intracranial extension. B: The appearance of the scar 3 weeks postoperatively. C: The appearance of the scar 27 months postoperatively, showing good cosmesis. Figure is available in color online only. 


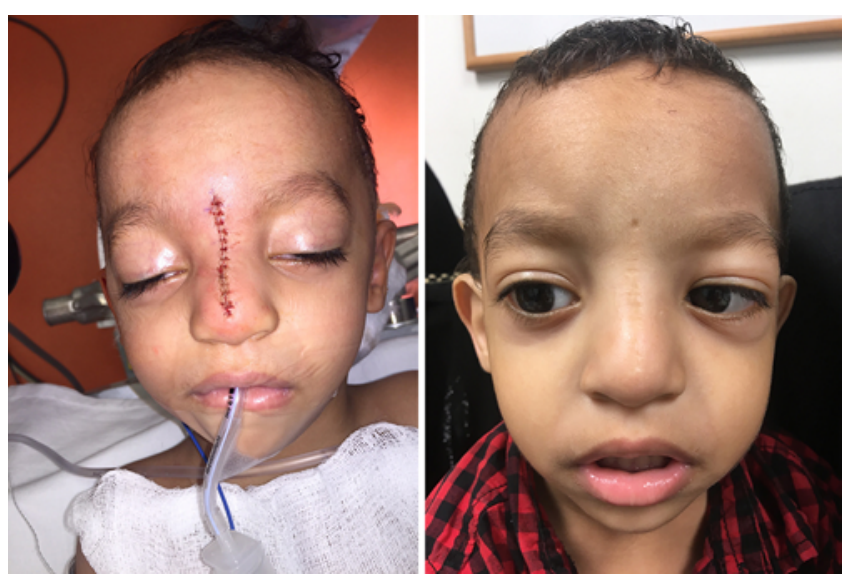

FIG. 12. Left: Intraoperative image after excision of a nasal dermoid cyst with intracranial extension. Right: The appearance of the scar 1 year postoperatively, showing good cosmesis. Figure is available in color online only.

ture this. However, some form of nasal osteotomy is often required in order to adequately excise a dermoid sinus in many techniques, including frontal craniotomies.

\section{Conclusions}

We present our technique for excision of nasal dermoid cysts with intracranial extension. The use of a vertical midline incision, nasal bone removal, and a keyhole craniotomy allows for wide access to the dermoid stalk, while minimizing complications, the need for transfusions, and hospital length of stay. This technique offers a balance between the wide intracranial exposure of a traditional frontal craniotomy and the low complication profile of minimally invasive approaches.

\section{References}

1. Bradley PJ: The complex nasal dermoid. Head Neck Surg 5:469-473, 1983

2. Hanikeri M, Waterhouse N, Kirkpatrick N, Peterson D, Macleod I: The management of midline transcranial nasal dermoid sinus cysts. Br J Plast Surg 58:1043-1050, 2005

3. Hartley BE, Eze N, Trozzi M, Toma S, Hewitt R, Jephson C, et al: Nasal dermoids in children: a proposal for a new classification based on 103 cases at Great Ormond Street Hospital. Int J Pediatr Otorhinolaryngol 79:18-22, 2015

4. Heywood RL, Lyons MJ, Cochrane LA, Hayward R, Hartley BE: Excision of nasal dermoids with intracranial extensionanterior small window craniotomy approach. Int J Pediatr Otorhinolaryngol 71:1193-1196, 2007

5. Holzmann D, Huisman TA, Holzmann P, Stoeckli SJ: Surgical approaches for nasal dermal sinus cysts. Rhinology 45:31-35, 2007

6. Jung TM, Terkonda RP, Haines SJ, Strome S, Marentette LJ: Outcome analysis of the transglabellar/subcranial approach for lesions of the anterior cranial fossa: a comparison with the classic craniotomy approach. Otolaryngol Head Neck Surg 116:642-646, 1997

7. Kellman RM, Goyal P, Rodziewicz GS: The transglabellar subcranial approach for nasal dermoids with intracranial extension. Laryngoscope 114:1368-1372, 2004

8. Kellman RM, Marentette L: The transglabellar/subcranial approach to the anterior skull base: a review of 72 cases. Arch Otolaryngol Head Neck Surg 127:687-690, 2001
9. Manickavasagam J, Robins JM, Sinha S, Mirza S: Endoscopic removal of a dermoid cyst via scalp incision. Laryngoscope 123:1862-1864, 2013

10. Moore CE, Ross DA, Marentette LJ: Subcranial approach to tumors of the anterior cranial base: analysis of current and traditional surgical techniques. Otolaryngol Head Neck Surg 120:387-390, 1999

11. Ortlip T, Ambro BT, Pereira KD: Midline approach to pediatric nasofrontal dermoid cysts. JAMA Otolaryngol Head Neck Surg 141:174-177, 2015

12. Pinheiro-Neto CD, Snyderman CH, Fernandez-Miranda J, Gardner PA: Endoscopic endonasal surgery for nasal dermoids. Otolaryngol Clin North Am 44:981-987, ix, 2011

13. Pollock RA: Surgical approaches to the nasal dermoid cyst. Ann Plast Surg 10:498-501, 1983

14. Posnick JC, Bortoluzzi P, Armstrong DC, Drake JM: Intracranial nasal dermoid sinus cysts: computed tomographic scan findings and surgical results. Plast Reconstr Surg 93:745-756, 1994

15. Rahbar R, Shah P, Mulliken JB, Robson CD, Perez-Atayde $\mathrm{AR}$, Proctor MR, et al: The presentation and management of nasal dermoid: a 30-year experience. Arch Otolaryngol Head Neck Surg 129:464-471, 2003

16. Re M, Tarchini P, Macrì G, Pasquini E: Endonasal endoscopic approach for intracranial nasal dermoid sinus cysts in children. Int J Pediatr Otorhinolaryngol 76:1217-1222, 2012

17. Rogers GF, Proctor MR, Greene AK, Mulliken JB: Frontonasal osteotomy to facilitate removal of an intracranial nasal dermoid. J Craniofac Surg 16:731-736, 2005

18. Schuster D, Riley KO, Cure JK, Woodworth BA: Endoscopic resection of intracranial dermoid cysts. J Laryngol Otol 125:423-427, 2011

19. Seidel DU, Sesterhenn AM: Intracranial nasal dermoid sinus cyst: transnasal endoscopic resection by open rhinoplasty approach, with intraoperative video. J Craniofac Surg 27:2110-2112, 2016

20. Uchida Y, Udagawa A, Suzuki H, Mitsukawa N, Numata O, Ito C: The "stepped caudal exposure" technique for excision of nasal dermoids with intracranial extension. J Craniofac Surg 25:648-651, 2014

21. van Aalst JA, Luerssen TG, Whitehead WE, Havlik RJ: "Keystone" approach for intracranial nasofrontal dermoid sinuses. Plast Reconstr Surg 116:13-19, 2005

22. Weiss DD, Robson CD, Mulliken JB: Transnasal endoscopic excision of midline nasal dermoid from the anterior cranial base. Plast Reconstr Surg 102:2119-2123, 1998

23. Zapata S, Kearns DB: Nasal dermoids. Curr Opin Otolaryngol Head Neck Surg 14:406-411, 2006

\section{Disclosures}

Dr. Corcoran reports owning stock in Immersive Touch.

\section{Author Contributions}

Conception and design: Rastatter, Purnell, Alden, Corcoran. Acquisition of data: Rastatter, Purnell. Analysis and interpretation of data: Rastatter, Purnell, Skladman. Drafting the article: Purnell, Skladman. Critically revising the article: Rastatter, Purnell, Alden, Corcoran. Reviewed submitted version of manuscript: all authors. Approved the final version of the manuscript on behalf of all authors: Purnell. Statistical analysis: Rastatter, Purnell. Administrative/technical/material support: Rastatter, Purnell. Study supervision: Rastatter, Purnell.

\section{Correspondence}

Jeffrey C. Rastatter: Ann \& Robert H. Lurie Children's Hospital of Chicago, IL. jrastatter@luriechildrens.org. 